\title{
Article \\ Seismic Performance Evaluation of Steel Buildings with Oil Dampers Using Capacity Spectrum Method
}

\author{
Ahmad Naqi (1) and Taiki Saito * \\ Department of Architecture and Civil Engineering, Toyohashi University of Technology, Aichi 441-8580, Japan; \\ ahmad.naqi.sl@tut.jp \\ * Correspondence: saito.taiki.bv@tut.jp
}

check for updates

Citation: Naqi, A.; Saito, T. Seismic Performance Evaluation of Steel Buildings with Oil Dampers Using Capacity Spectrum Method. Appl. Sci. 2021, 11, 2687. https://doi.org/ 10.3390/app11062687

Academic Editors: Felice Carlo Ponzo and Antonio Di Cesare

Received: 21 February 2021

Accepted: 13 March 2021

Published: 17 March 2021

Publisher's Note: MDPI stays neutral with regard to jurisdictional claims in published maps and institutional affiliations.

Copyright: (c) 2021 by the authors. Licensee MDPI, Basel, Switzerland. This article is an open access article distributed under the terms and conditions of the Creative Commons Attribution (CC BY) license (https:// creativecommons.org/licenses/by/ $4.0 /)$.

\begin{abstract}
This study proposes a capacity spectrum Method (CSM)-based procedure to estimate the maximum seismic performance of steel buildings passively controlled with bilinear oil dampers. In the proposed CSM, the maximum seismic response of a building was estimated, in the accelerationdisplacement response spectrum, as the intersection between the capacity curve and the dampingadjusted demand curves, using the equivalent linearization method. The building equivalent damping ratio was determined by the sum of the inherent damping, and the square root of sum of squares (SRSS) of the hysteretic damping and the viscous damping of the supplemental oil devices. The calculation steps of the proposed CSM are explained in detail based on the equivalent single degree of freedom (ESDOF) system, and its accuracy was examined by comparison with time history analysis (THA) results. Two model steel buildings of 4 and 10 stories, uniformly equipped with oil dampers along the height, were subjected to six selected earthquake ground motions scaled to be compatible with Level-2 earthquakes, as defined in the Japanese Building Standard Law. The seismic performance of the buildings was estimated by the proposed CSM procedure and compared with the results of nonlinear THA in terms of the maximum story displacements and the shear forces. It was observed that the proposed CSM scheme provided a satisfactory accuracy to assess the maximum nonlinear response of steel buildings passively controlled with oil dampers.
\end{abstract}

Keywords: bilinear oil damper; steel structure; capacity spectrum method; passively controlled buildings

\section{Introduction}

The capacity spectrum method (CSM) is a practical tool to evaluate the seismic performance of buildings using a response spectrum and an equivalent linear system. Since its original development by Freeman in 1975, it has been modified and adopted by different organizations [1]. For instance, in 1980, the Applied Technology Council (ATC) published guidelines to evaluate building performance using the CSM concept [2]. Similarly, in 1998, the Building Standard Law of Japan adopted the concept of CSM as one of the procedures for the seismic design of buildings [3]. Likewise, many researchers have assessed the accuracy of the method and applied it over a wide range of structural systems [4]. Consequently, a number of modifications have been proposed to improve the application of CSM depending on the structural type of buildings.

Generally, the seismic assessment and design of structures equipped with damping devices require nonlinear time history analysis (THA), which is highly time-consuming. Some straightforward procedures have been proposed by researchers to evaluate the seismic performance of passively controlled buildings. Choi and Kim [5] developed a CSM-based procedure to estimate the amount of supplemental viscous damping, for a multi-story building, required to reduce roof displacement in the range of pre-defined target displacement. A similar concept is further illustrated by Kim et al. [6], and Li and Liang [7]. The study conducted by Chen et al. [7,8] introduced an improved version of 
CSM to estimate the number of metallic dampers under earthquake loads. In the cases of the buildings with viscoelastic dampers, Han et al. [9] employed CSM to analyze the performance of the passively controlled buildings. Benavent-Climent and EscolanoMargarit [10] compared shaking table test results of the scaled specimens equipped with hysteretic dampers and those obtained by the improved CSM procedures, and it was reported that the improved CSM had the potential to estimate maximum displacement with acceptable accuracy. Kim et al. [11] discussed the optimal distribution of steel dampers along the height of the structures using the CSM procedure. Kosmas et al. [12] proposed an alternative CSM method using the constant ductility inelastic spectra to estimate the seismic performance of structures with viscous dampers. Joao Estevao [13] incorporated the CSM method to investigate the seismic risk of buildings in a seismically active region using capacity curves of individual buildings. Furthermore, the effectiveness of CSM to design and evaluate the retrofitting of RC buildings is extensively discussed and reported by researchers [14,15]. Ramirez et al. [16] proposed the following two simplified procedures, similar to CSM: the equivalent lateral force (ELF) and response spectrum procedures (RSP), which are adopted in the 2000 NEHRP and ASCE7 provisions for the design of passively controlled buildings. In the ELF method, the contributions of the first mode and residual mode are incorporated, whereas in the RSP method, the contributions of higher modes are also considered to estimate the response of buildings with damping devices.

The oil damper device (OD) is widely used due to its excellent performance, including its durability of aging, durability under repeated loading cycles, low temperature dependence, high energy dissipation capacity, and stable mechanical properties [17-20]. The bilinear-type oil damper, which has a relief valve and reduces the rate of increase in damping force when the relief velocity is exceeded, is commonly used in Japan, especially for high-rise buildings. Adachi et al. [21,22] introduced a design procedure to minimize the story drift and acceleration of high-rise buildings by optimizing the OD relief force distribution along the height of the building. Ji et al. [23] reported about the contribution of OD in a real size five-story steel building, tested on the E-defense shaking table in Japan. Xie et al. [24] examined the performance of an eight-story steel building equipped with oil dampers damaged during the 2011 Great East Japan Earthquake. Takabatake and Kitada [25] proposed a simplified procedure to evaluate the seismic performance of a retrofitted building with OD installed inside and outside of the structural frame.

Although the seismic performance of buildings with hysteretic and viscous dampers are studied extensively, few studies have been conducted on the CSM methods for passively controlled buildings with bilinear-type oil dampers. Therefore, this study proposes a CSMbased method to estimate the maximum responses of passively controlled buildings with bilinear-type oil dampers, and the results are compared with those of nonlinear THA.

\section{Proposal of the Square Root of Sum of Squares (SRSS) Effective Damping Ratio}

The equivalent damping ratio, $h_{h}$, of a hysteresis damper is defined [26] as,

$$
h_{h}(\mu)=\frac{1}{4 \pi} \frac{\Delta W_{h}}{W}
$$

where $\Delta W_{h}$ is the hysteresis energy under one cycle of hysteresis and $W$ is the area of elastic strain energy. For the bilinear hysteresis, as shown in Figure 1a, they are obtained as,

$$
\begin{gathered}
\Delta W_{h}=4 K \delta_{y}^{2}(\mu-1)(1-p) \\
W=\frac{1}{2} K \delta_{y}^{2} \mu^{2}
\end{gathered}
$$




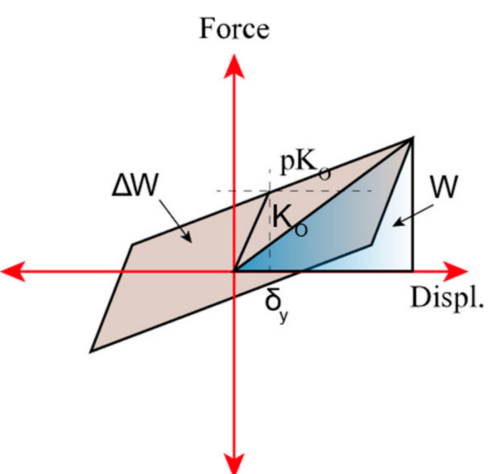

(a)

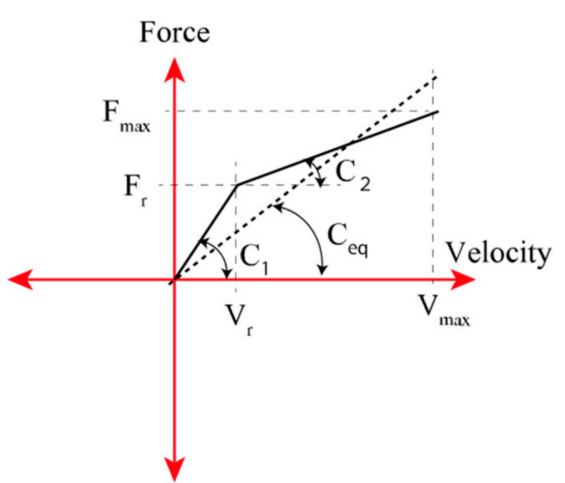

(b)

Figure 1. (a) The force-displacement relation of the bilinear hysteresis model; (b) the force-velocity relation of bilinear-type oil damper.

In the Equations (2) and (3), $\delta_{y}$ is the yield displacement of the system, $\mu$ is a displacement ductility factor, $K$ is the initial stiffness, and $p$ is the ratio of post-yield to pre-yield stiffness.

In the same way, the equivalent damping ratio, $h_{V}$, of an oil damper is defined as

$$
h_{v}(\mu)=\frac{1}{4 \pi} \frac{\Delta W_{v}}{W}
$$

where $\Delta W_{V}$ is the area of one cycle of force-velocity relation of the oil damper, given by,

$$
\Delta W_{v}=\pi C \omega \mu^{2} \delta_{y}^{2}
$$

where $C$ is the damping coefficient of the oil damper and $\omega$ is the equivalent circular frequency of the system.

In the system with a hysteresis damper and an oil damper, according to the Building Standard Law of Japan [3], the effective damping ratio, $h_{\text {eff, }}$ of a seismically isolated building is defined by the direct sum of three types of damping ratios as given in Equation (6).

$$
h_{e f f, \text { Direct }}=h_{0}+h_{h}+h_{v}
$$

where $h_{0}$ is the inherent damping ratio.

Kasai et al. $[27,28]$ proposed a formula of the effective damping ratio as the average of the equivalent damping ratio in the range of 0 to $\mu$ as given in Equation (7). It is reported that the accuracy of this formula is relatively high to estimate the earthquake response of the system. However, it is difficult to obtain an explicit analytical solution for the general hysteresis model.

$$
h_{e f f, \text { Kasai }}=\frac{1}{\mu} \int_{0}^{\mu} h_{e q}\left(\mu^{\prime}\right) d \mu^{\prime}=\frac{1}{\mu} \int_{0}^{\mu}\left(h_{h}\left(\mu^{\prime}\right)+h_{v}\left(\mu^{\prime}\right)\right) d \mu^{\prime}
$$

The current research study proposed a formula to calculate the effective damping ratio from the sum of the inherent damping, and the SRSS of the equivalent hysteresis and viscous damping ratios as given in Equation (8).

$$
h_{e f f, S R S S}=h_{0}+\sqrt{h_{h}^{2}+h_{v}^{2}}
$$

The comparison of the values of the effective damping ratio for the three procedures ( $h_{\text {eff,Direct }}, h_{\text {eff,SRSS, }}$ and $h_{\text {eff,Kasai }}$ ) with respect to the ductility factor is shown in Figure 2, where the post-yield stiffness ratio, $p$, and the initial damping factor, $h_{0}$, are varied as $p=0.01 \sim 0.05$ and $h_{0}=0.05 \sim 0.3$. It is depicted that the proposed $h_{\text {eff }, \text { SRSS }}$ becomes closer to 
the value of $h_{\text {eff,Kasai }}$ as $h_{0}$ increases. On the other hand, $h_{\text {eff,Direct }}$ overestimates the effective damping ratio by $30 \%$ compared to $h_{\text {eff, Kasai }}$.

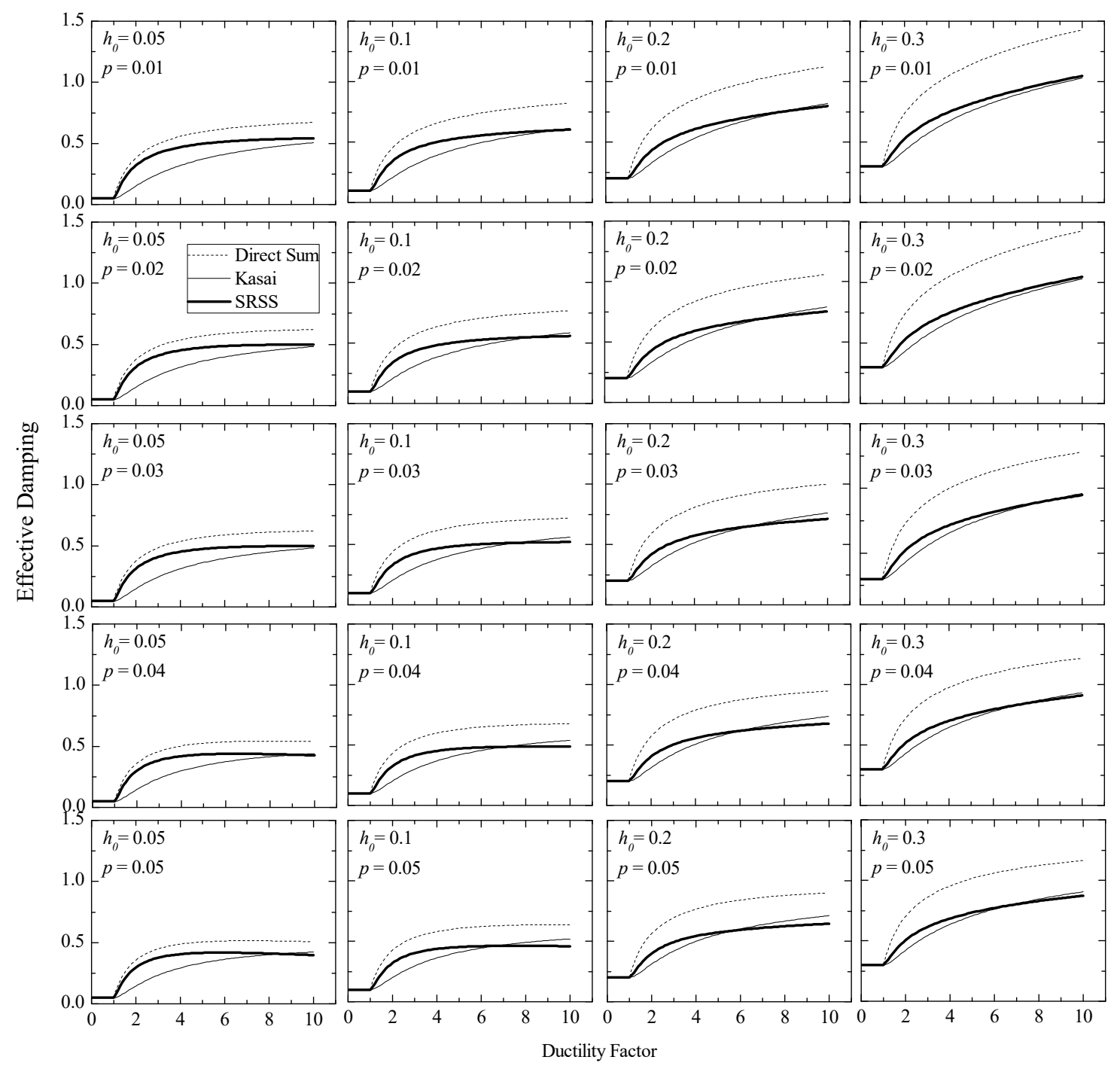

Figure 2. Comparison of different procedures to estimate the effective damping ratio.

In the case of the bilinear-type oil damper, the equivalent damping coefficient, $C_{e q}$, is proposed in the JSSI manual so that the area under the equivalent linear damping should be equal to the area of bilinear force-velocity relation as shown in Figure 1b [17], and derived as

$$
C_{e q}=\frac{C_{1}}{\mu *^{2}}+C_{2}\left(1-\frac{1}{\mu *}\right)^{2}+\frac{2 C_{1}}{\mu *}\left(1-\frac{1}{\mu *}\right)
$$

where, in Equation (9), $C_{1}$ and $C_{2}$ are the pre-relief and post-relief damping coefficients of the bilinear-type oil damper, and $\mu *$ is the ratio of maximum velocity to relief velocity. In the subsequent sections, the proposed $h_{\text {eff,SRSS }}$, which is obtained from $C_{e q}$, is used to evaluate the maximum seismic performance of a steel building by CSM.

\section{Proposed CSM Procedure for Buildings Equipped with Oil Dampers}

This section demonstrates the procedure of the proposed CSM using the equivalent single degree of freedom (ESDOF) system defined by Kuramoto et al., 2000 [29]. The ESDOF consists of a mass, $m$, a frame damping coefficient, $C_{f}$, and a stiffness, $K_{f}$. This study assumed that the natural period of the ESDOF was $0.5 \mathrm{~s}$ and the base shear coefficient (i.e., 
the ratio of yielding force to the total weight) was 0.2. The ESDOF was equipped with the bilinear-type oil damper which had a damping coefficient, $C_{D}$, and a stiffness, $K_{D}$, as shown in Figure 3a. The ESDOF parameters are summarized in Tables 1 and 2.

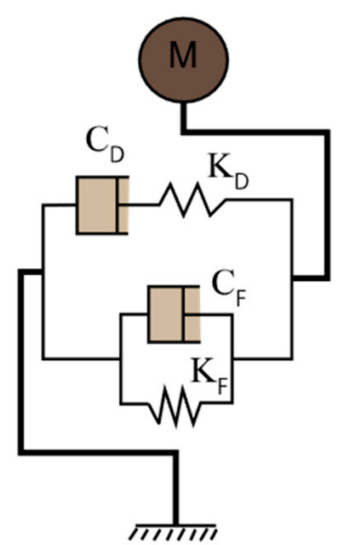

(a)

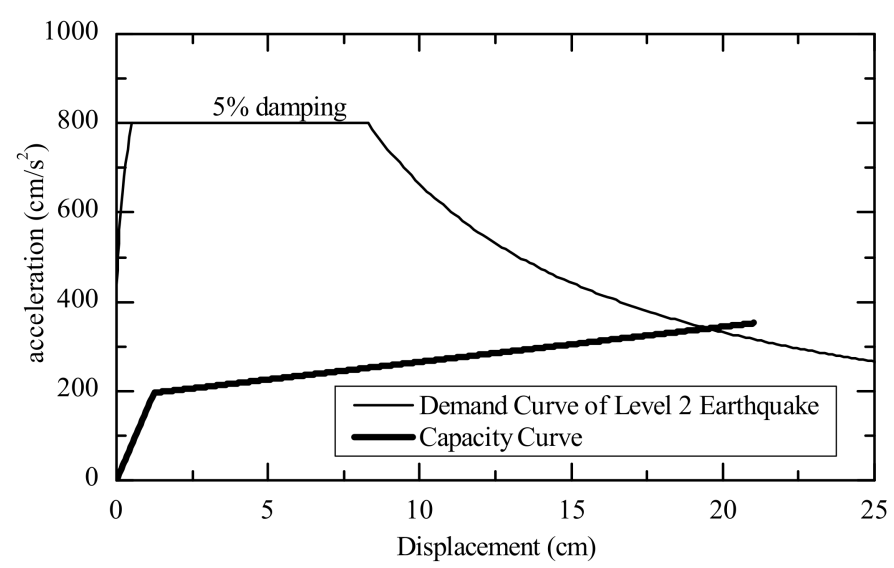

(b)

Figure 3. (a) The equivalent oil damper configuration in the ESDOF system; (b) the initial demand curve (5\% damping) and capacity curve of the ESDOF system.

Table 1. Technical parameters of the equivalent single degree of freedom (ESDOF) system.

\begin{tabular}{|c|c|c|c|c|c|}
\hline $\begin{array}{l}\text { Natural Period } \\
\text { (T) }\end{array}$ & $\begin{array}{c}\text { Weight } \\
\text { (W) }\end{array}$ & $\begin{array}{c}\text { Damping } \\
\left(\mathrm{h}_{0}\right)\end{array}$ & $\begin{array}{l}\text { Stiffness } \\
\left(\mathrm{K}_{\mathrm{f}}\right)\end{array}$ & $\begin{array}{l}\text { Yielding } \\
\text { Force }\left(F_{y}\right)\end{array}$ & $p={\frac{K_{2}}{K_{1}}}$ \\
\hline $\mathbf{s}$ & $\mathbf{k N}$ & $\%$ & $\mathrm{kN} / \mathrm{cm}$ & kN & \\
\hline 0.5 & 5000.0 & 5.0 & 805.68 & 1000.0 & 0.05 \\
\hline
\end{tabular}

Table 2. Technical parameters of the supplemental story-equivalent oil damper.

\begin{tabular}{|c|c|c|c|}
\hline $\begin{array}{l}\text { Stiffness } \\
\left(K_{D}\right)\end{array}$ & $\begin{array}{l}\text { Pre-Relief Damping Coef. } \\
\qquad\left(C_{1}\right)\end{array}$ & $\begin{array}{l}\text { Relief Velocity } \\
\left(V_{r}\right)\end{array}$ & $C_{2} / C_{1} *$ \\
\hline $\mathrm{kN} / \mathrm{cm}$ & $\mathrm{kN}-\mathrm{s} / \mathrm{cm}$ & $\mathrm{cm} / \mathrm{s}$ & \\
\hline 805.68 & 22.0 & 5.0 & 0.05 \\
\hline
\end{tabular}

The capacity curve of the system is shown in Figure $3 b$. The demand curve is presented in the form of an acceleration-displacement spectrum of the selected earthquake ground motion. In this study, the Level-2 earthquake defined in the Building Standard Law of Japan [3] was used to generate the design acceleration-displacement response spectrum with a $5 \%$ damping factor. The latter was adjusted according to the value of the effective damping using the reduction factor, $F_{h}$, in Equation (10), adopted by the JSSI manual [17] from the study conducted by Kasai et al. [28,30].

$$
F_{h}=\frac{\sqrt{1+25 h_{5 \%}}}{\sqrt{1+25 h_{e f f}}}
$$

The proposed CSM was performed as following:

- $\quad$ The multi degree of freedom (MDOF) was converted to the ESDOF [29];

- For selected ductility factor values (e.g., $\mu=1,2,3 \ldots$ ), the respective effective damping ratios (e.g., $h_{1}, h_{2}, h_{3} \ldots$ ), not including the contribution of the oil damper 
devices, were computed using Equation (11) [3], and the demand spectra were adjusted by Equation (10), and plotted together with the capacity curve of the ESDOF as shown in Figure 4a;

$$
h_{e q}=0.8 \frac{2}{\pi}\left(1-\frac{1}{\mu}\right) \frac{1-p}{1+p(\mu-1)}+0.05
$$

- The spectral ordinates (spectral acceleration, $S_{A}$, and displacement, $S_{D}$ ) of the demand spectrum at the intersection points with equivalent stiffness lines were determined and named as initial performance points;

- For each initial performance point, the equivalent circular frequency of the ESDOF was estimated by Equation (12);

$$
\omega_{e q}(\mu)=\sqrt{\frac{S_{A}}{S_{D}}}
$$

- The corresponding story displacements $\left(\delta_{1}, \delta_{2}, \delta_{3} \ldots\right)$ were computed from the ESDOF. Then, the maximum story velocities of the MDOF, $V_{\max }$, were estimated as following;

$$
V_{\text {max }, i}(\mu)=\omega_{e q} \cdot \delta_{i}
$$

- Using Equations (8), (9) and (16) the effective damping of the system, $h_{\text {eff,SRSS, }}$, the equivalent damping coefficient, $C_{e q}$, and the viscous damping of oil dampers, $h_{V}$, were estimated, respectively;

- Demand spectra were updated for each ductility factor as shown in Figure $4 b$ (dashedline response spectra);

- The next performance points were considered, and the same process was repeated until convergence (the difference between successive effective damping ratios becomes negligible), as shown in Figure 4c (dashed-dotted-line response spectra);

- The final performance points were connected and the point of intersection of the formed curve (blue solid line in Figure 4d) with the capacity curve was defined as the ultimate performance point of the ESDOF;

- Maximum seismic performance of the corresponding MDOF could be deducted from the ultimate performance point of its ESDOF.

For the ESDOF system presented in this section, the maximum displacement was estimated as $6.15 \mathrm{~cm}$. In Figure $4 \mathrm{~d}$, the average maximum displacements from the THA of six selected Level-2 earthquakes (details are given in Section 4.4) are marked by a vertical broken line. A difference of $20 \%$ was observed from the proposed CSM result. 


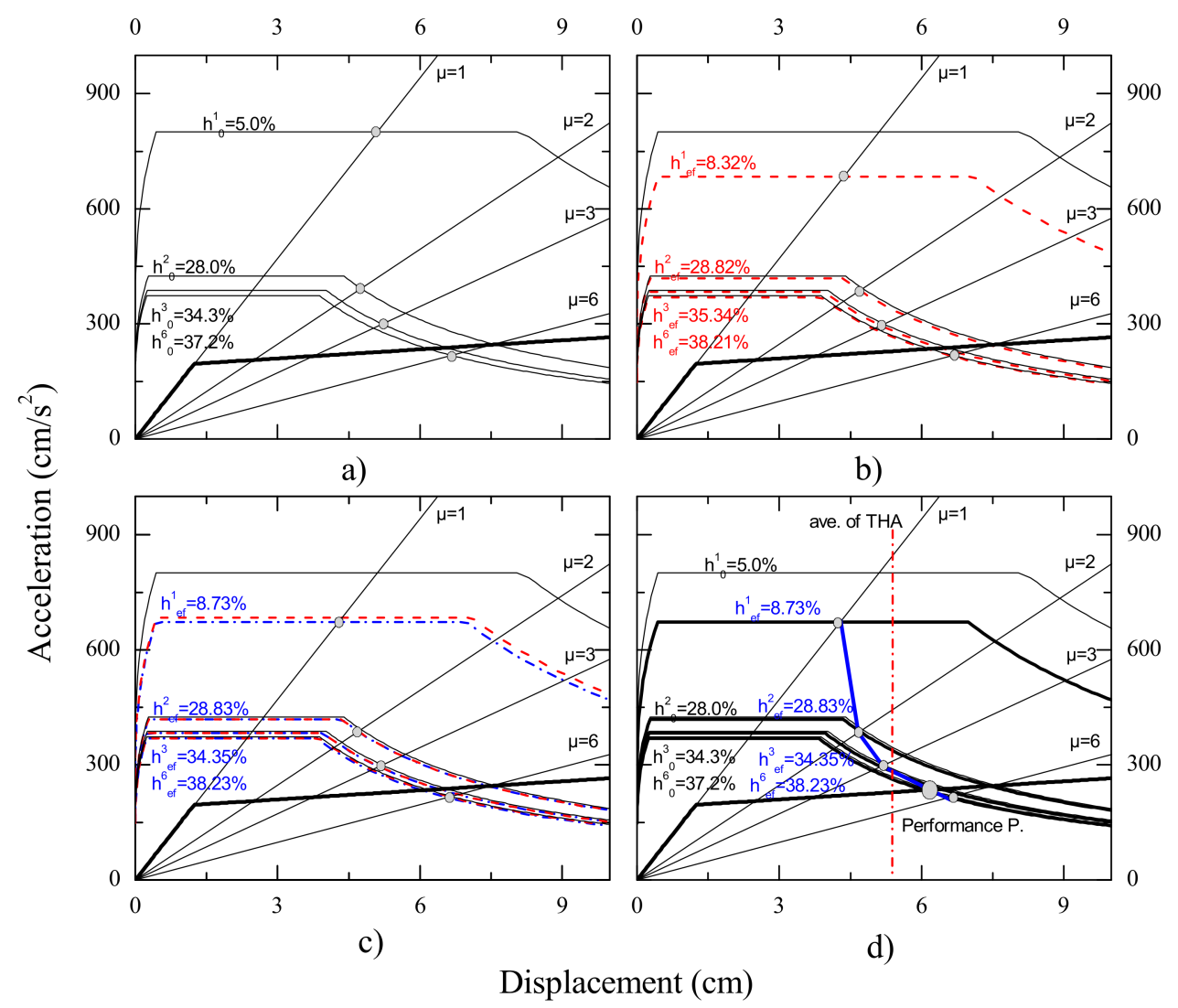

Figure 4. (a-d) steps of the proposed capacity spectrum method (CSM) applied to the ESDOF system using the damping-adjusted design spectra of a Level-2 earthquake.

\section{Application of the Proposed CSM on Steel Frame Buildings}

\subsection{Effective Damping Ratio of MDOF System}

Where the oil dampers were arranged in a diagonal scheme with the inclination angle, $\theta$, for an MDOF system as illustrated in Figure 5, the Equations (4) and (5) can be used to incorporate the oil damper distribution along the building height, as follows:

$$
\begin{aligned}
\sum \Delta W_{j} & =\pi \cdot \omega_{e q} \sum C_{j} \phi_{r j}^{2} \cos \theta_{j}^{2} \\
\mathrm{~W} & =\frac{1}{2} \omega_{e q}^{2} \sum m_{j} \Delta_{j}^{2}
\end{aligned}
$$

where $C_{j}, \Delta_{j}, \phi_{r j}, \omega_{e q}$ and $m_{j}$ are the damping coefficient of the oil damper, the story drift of the first mode, the relative story drift, the equivalent circular frequency and the mass of $j$ th floor, respectively. By substituting Equations (14) and (15) into Equation (4), the viscous damping ratio of the oil damper can be obtained as given in Equation (16) for an MDOF system.

$$
h_{V}=\frac{1}{2} \frac{\sum C_{j} \phi_{r j}^{2} \cos \theta_{j}^{2}}{\omega_{e q} \sum m_{j} \Delta_{j}^{2}}
$$

\subsection{Description of Target Buildings}

Steel buildings, both 4 -story and 10-story, were selected from the JSSI manual $[17,31]$. The buildings were designed as steel moment-resisting frames to resist the gravity loads, while oil dampers were considered to control the response under the earthquake ground motion. The plans and elevations of the buildings are shown in Figure 6. The ground floor height is $6 \mathrm{~m}$, and the typical floor height is $4 \mathrm{~m}$ for both target buildings. The sizes of columns and beams are summarized in Tables 3 and 4 . 


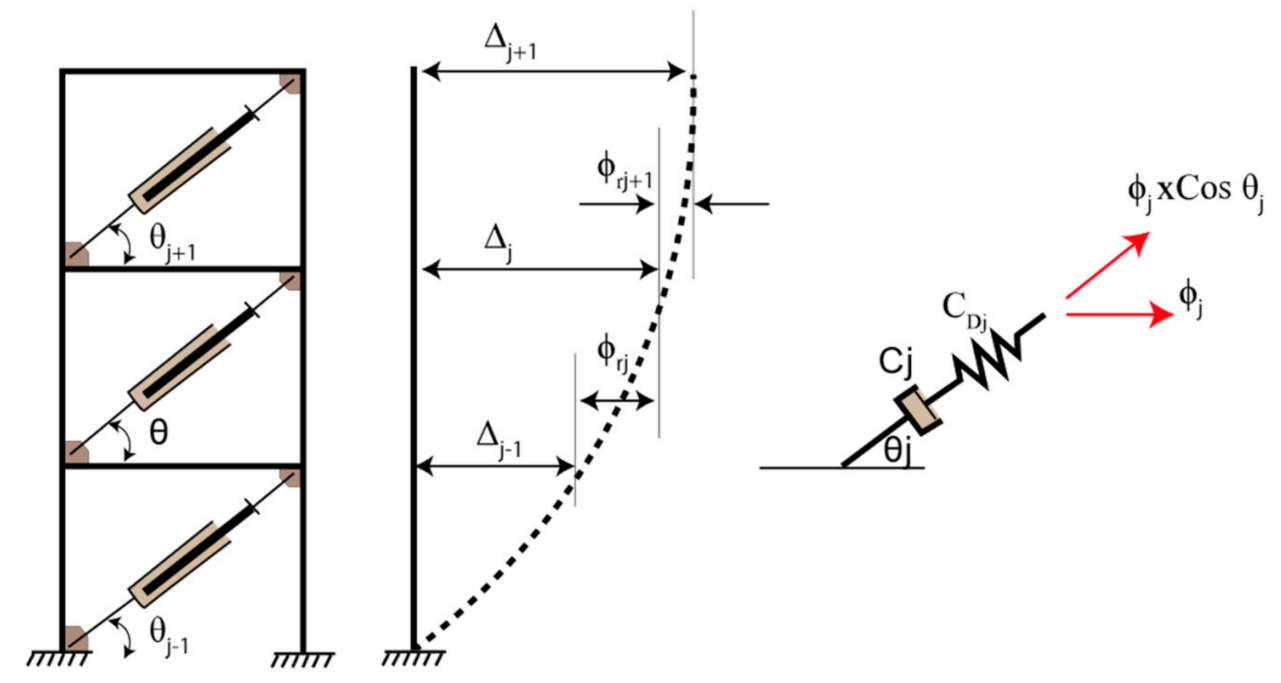

Figure 5. Multi degree of freedom (MDOF) with oil dampers corresponding to the first mode of vibration.
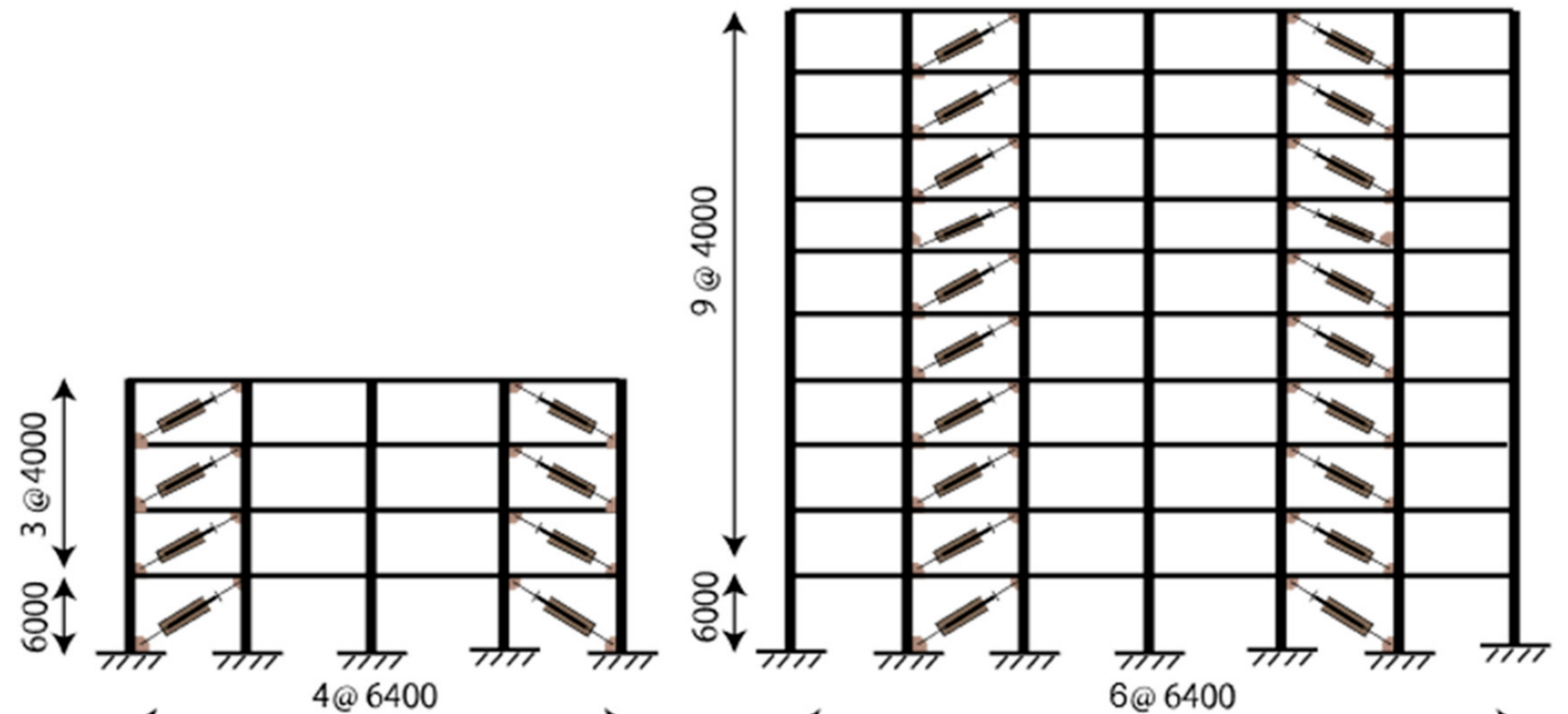

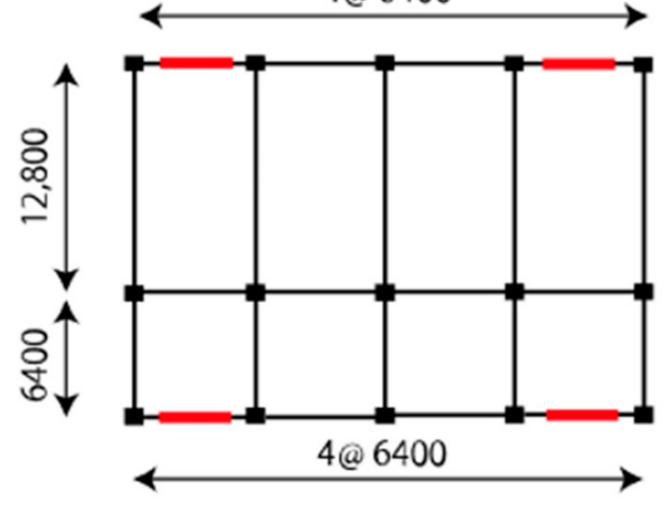

(a)

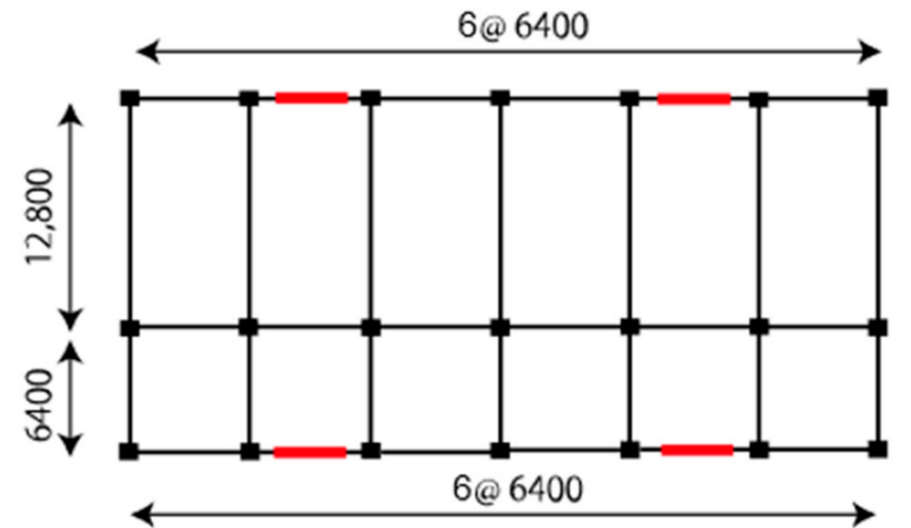

(b)

Figure 6. Target buildings plan, elevation and oil damper configuration: (a) 4-story building; (b) 10-story building. 
Table 3. Detail and size of structural columns (mm).

\begin{tabular}{ccccc}
\hline Building & Story & Interior Column & Exterior Column & Corner Column \\
\hline \multirow{4}{*}{ 4-story } & 4 & $400 \times 400 \times 16$ & $400 \times 400 \times 16$ & $350 \times 350 \times 16$ \\
& 3 & $450 \times 450 \times 19$ & $400 \times 400 \times 19$ & $350 \times 350 \times 16$ \\
& 2 & $450 \times 450 \times 22$ & $450 \times 450 \times 19$ & $400 \times 400 \times 19$ \\
1 & $500 \times 500 \times 22$ & $500 \times 500 \times 19$ & $400 \times 400 \times 19$ \\
\hline \multirow{3}{*}{ 10-story } & $7-\mathrm{R}$ & $550 \times 550 \times 22$ & $500 \times 500 \times 22$ & $500 \times 500 \times 19$ \\
& $5-6$ & $600 \times 600 \times 28$ & $550 \times 550 \times 25$ & $550 \times 550 \times 22$ \\
& $3-4$ & $650 \times 650 \times 28$ & $600 \times 600 \times 25$ & $600 \times 600 \times 22$ \\
& 2 & $650 \times 650 \times 28$ & $600 \times 600 \times 28$ & $600 \times 600 \times 25$ \\
\hline
\end{tabular}

Table 4. Detail and size of structural beams (mm).

\begin{tabular}{cccccc}
\hline \multirow{2}{*}{ Building } & Story & \multicolumn{2}{c}{ Longitudinal Direction } & \multicolumn{2}{c}{ Transvers Direction } \\
\cline { 2 - 6 } & 4 & Interior Beam & Exterior Beam & Short Span & Long Span \\
\hline \multirow{2}{*}{ 4-story } & 3 & $550 \times 200 \times 9 \times 16$ & $550 \times 250 \times 12 \times 22$ & $700 \times 300 \times 12 \times 22$ \\
& 2 & $600 \times 250 \times 12 \times 22$ & $550 \times 200 \times 12 \times 22$ & $700 \times 250 \times 12 \times 22$ \\
& 1 & $650 \times 250 \times 12 \times 25$ & $600 \times 200 \times 12 \times 25$ & $750 \times 250 \times 14 \times 25$ \\
& $10-\mathrm{R}$ & $600 \times 300 \times 12 \times 22$ & $600 \times 250 \times 12 \times 22$ & $600 \times 300 \times 14 \times 25$ & $600 \times 300 \times 14 \times 32$ \\
& $8-9$ & $700 \times 300 \times 12 \times 22$ & $700 \times 250 \times 12 \times 22$ & $700 \times 300 \times 14 \times 25$ & $700 \times 300 \times 16 \times 32$ \\
10 -story & $6-7$ & $750 \times 300 \times 16 \times 25$ & $750 \times 250 \times 14 \times 25$ & $750 \times 300 \times 16 \times 28$ & $750 \times 300 \times 16 \times 32$ \\
& $4-5$ & $750 \times 300 \times 16 \times 28$ & $750 \times 250 \times 16 \times 28$ & $750 \times 350 \times 16 \times 28$ & $750 \times 350 \times 16 \times 32$ \\
& 3 & $750 \times 300 \times 16 \times 28$ & $750 \times 300 \times 16 \times 28$ & $750 \times 350 \times 16 \times 28$ & $750 \times 350 \times 16 \times 32$ \\
& 2 & $800 \times 300 \times 16 \times 32$ & $800 \times 300 \times 16 \times 28$ & $800 \times 300 \times 16 \times 32$ & $800 \times 300 \times 16 \times 32$ \\
\hline
\end{tabular}

The steel grade is SN490B with a yield strength of $325 \mathrm{MPa}$ and a tensile strength of $490 \mathrm{MPa}$. The arrangement of oil dampers in the plan and the evaluation of the building is shown in Figure 6. Since the oil dampers were diagonally installed in a longitudinal direction only, the following analysis is limited to the longitudinal direction. The technical parameters of oil dampers are presented in Tables 5 and 6.

Table 5. Technical parameters of oil dampers for 4-story building.

\begin{tabular}{cccccccc}
\hline \multirow{2}{*}{ Story } & $\begin{array}{c}\text { Height } \\
\mathbf{( H )}\end{array}$ & $\begin{array}{c}\text { Weight } \\
\left(\mathbf{W}_{\mathbf{f}}\right)\end{array}$ & $\begin{array}{c}\text { Story Stiffness } \\
\left(\mathbf{K}_{\mathbf{F}}\right)\end{array}$ & $\begin{array}{c}\text { Damper Stiffness } \\
\left(\mathbf{K}_{\mathbf{D}}\right)\end{array}$ & $\begin{array}{c}\text { Damping } \\
\left(\mathbf{C}_{\mathbf{1}}\right)\end{array}$ & $\begin{array}{c}\text { Relief V. } \\
\left(\mathbf{V}_{\mathbf{r}}\right)\end{array}$ & $\boldsymbol{C}_{\mathbf{2}} / \boldsymbol{C}_{\mathbf{1}}$ \\
\cline { 2 - 6 } & $\mathbf{m}$ & $\mathbf{k N}$ & $\mathbf{k N} / \mathbf{m m}$ & $\mathbf{k N} / \mathbf{m m}$ & $\mathbf{k N}-\mathbf{s} / \mathbf{m m}$ & $\mathbf{c m} / \mathbf{s}$ \\
\hline 4 & 4.0 & 6622.0 & 328.2 & 56.50 & 11.75 & 38.6 \\
3 & 4.0 & 6664.0 & 383.0 & 65.93 & 13.70 & 38.6 & 0.02 \\
2 & 4.0 & 6680.0 & 383.5 & 66.02 & 13.72 & 38.6 & 0.02 \\
1 & 6.0 & 6859.0 & 280.0 & 48.18 & 10.02 & 57.9 \\
\hline
\end{tabular}

\subsection{Frame Models of Target Buildings}

The 3D frame models of the buildings were analyzed by STERA_3D software, which is a finite element-based program developed by one of the authors [32]. In the model, the steel beam element is presented by a line element with two nonlinear flexural springs at both ends, as shown in Figure 7. The steel column element is presented by a line element with nonlinear axial springs in both end sections to consider nonlinear axial-moment interaction. The steelstrength was modified 1.1 times more than the nominal strength, and the ratio of post-yield stiffness was $\gamma=K_{0} / K_{y}=0.001$. The slab effects required to amplify the flexural stiffness of the steel beam were assumed to be 1.2. The floor slab was considered to be rigid for in-plane deformation, and free for out-of-plane deformation. The beam-column 
connection was assumed to be rigid, where the rigid zone length for the beam element was set to be half of the column width.

Table 6. Technical parameters of oil dampers for 10-story building.

\begin{tabular}{|c|c|c|c|c|c|c|c|}
\hline Story & Height (H) & Weight $\left(W_{f}\right)$ & $\begin{array}{c}\text { Story Stiffness } \\
\left(\mathrm{K}_{\mathrm{F}}\right)\end{array}$ & $\begin{array}{c}\text { Damper Stiffness } \\
\left(K_{D}\right)\end{array}$ & $\begin{array}{l}\text { Damping } \\
\qquad\left(C_{1}\right)\end{array}$ & Relief V. $\left(V_{r}\right)$ & \multirow[t]{2}{*}{$C_{2} / C_{1}$} \\
\hline & $\mathbf{m}$ & $\mathbf{k N}$ & $\mathrm{kN} / \mathrm{mm}$ & $\mathrm{kN} / \mathrm{mm}$ & $\mathrm{kN}-\mathrm{s} / \mathrm{mm}$ & $\mathrm{cm} / \mathrm{s}$ & \\
\hline 10 & 4.0 & 8579.0 & 158.6 & 27.30 & 5.67 & 38.6 & 0.02 \\
\hline 9 & 4.0 & 6365.0 & 180.1 & 31.00 & 6.45 & 38.6 & 0.02 \\
\hline 8 & 4.0 & 6431.0 & 220.3 & 37.92 & 7.88 & 38.6 & 0.02 \\
\hline 7 & 4.0 & 6470.0 & 244.8 & 42.13 & 8.77 & 38.6 & 0.02 \\
\hline 6 & 4.0 & 6539.0 & 291.8 & 50.23 & 10.45 & 38.6 & 0.02 \\
\hline 5 & 4.0 & 6567.0 & 306.2 & 52.70 & 10.95 & 38.6 & 0.02 \\
\hline 4 & 4.0 & 6622.0 & 328.2 & 56.50 & 11.75 & 38.6 & 0.02 \\
\hline 3 & 4.0 & 6664.0 & 383.0 & 65.93 & 13.70 & 38.6 & 0.02 \\
\hline 2 & 4.0 & 6680.0 & 383.5 & 66.02 & 13.72 & 38.6 & 0.02 \\
\hline 1 & 6.0 & 6859.0 & 280.0 & 48.18 & 10.02 & 57.9 & 0.02 \\
\hline
\end{tabular}

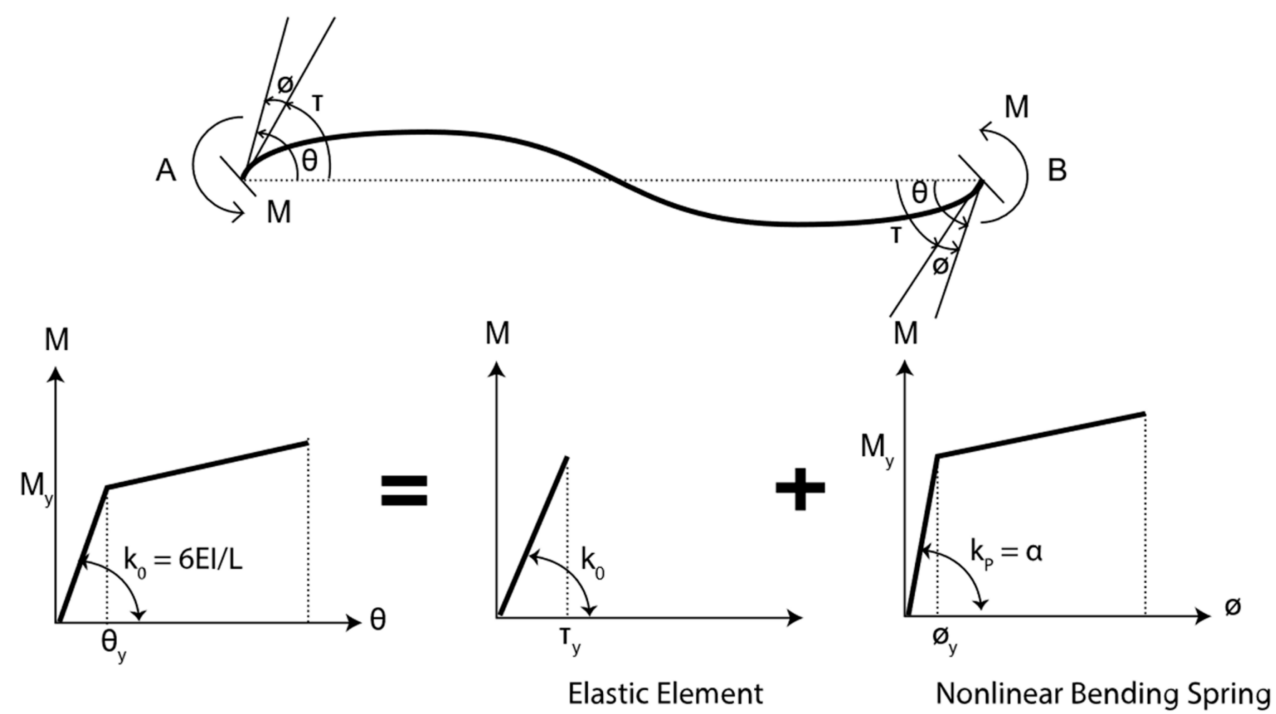

Figure 7. Moment-rotation relationship at bending spring of beam and column elements.

The bilinear-type oil damper is defined as a vertical line element with a shear spring in the middle. The shear spring consists of the Maxwell model with an elastic spring with stiffness, $K_{D}$, and a dashpot with a bilinear-type damping coefficient, $C$, connected in a series. The force-velocity relation of the dashpot is shown in Figure 8.

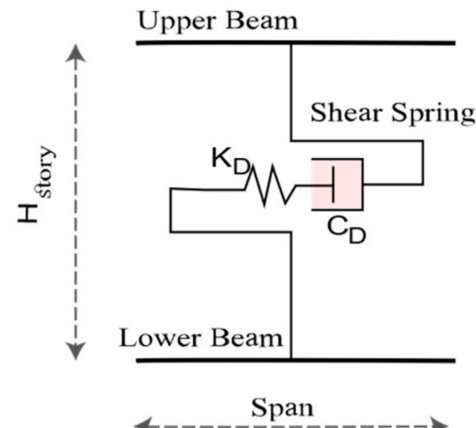

(a)

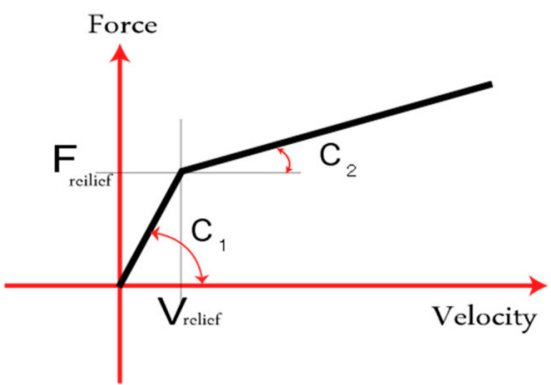

(b)

Figure 8. (a) Element model of bilinear-type oil damper, (b) force-velocity of oil damper. 
Table 7 summarizes the natural periods and effective masses of the buildings obtained by the eigenvalue analysis. The capacity curves of the ESDOF of the buildings were obtained by the nonlinear static pushover analysis as shown in Figure 9.

Table 7. Dynamic characteristics of target buildings.

\begin{tabular}{ccccc}
\hline Building & Parameter & 1st Mode & 2nd Mode & 3rd Mode \\
\hline \multirow{2}{*}{ 4-story } & Natural period (s) & 1.40 & 0.49 & 0.25 \\
& Effective mass (\%) & 91.2 & 7.90 & 0.60 \\
\hline \multirow{2}{*}{ 10-story } & Natural period (s) & 2.03 & 0.75 & 0.44 \\
& Effective mass (\%) & 82.8 & 11.3 & 3.40 \\
\hline
\end{tabular}
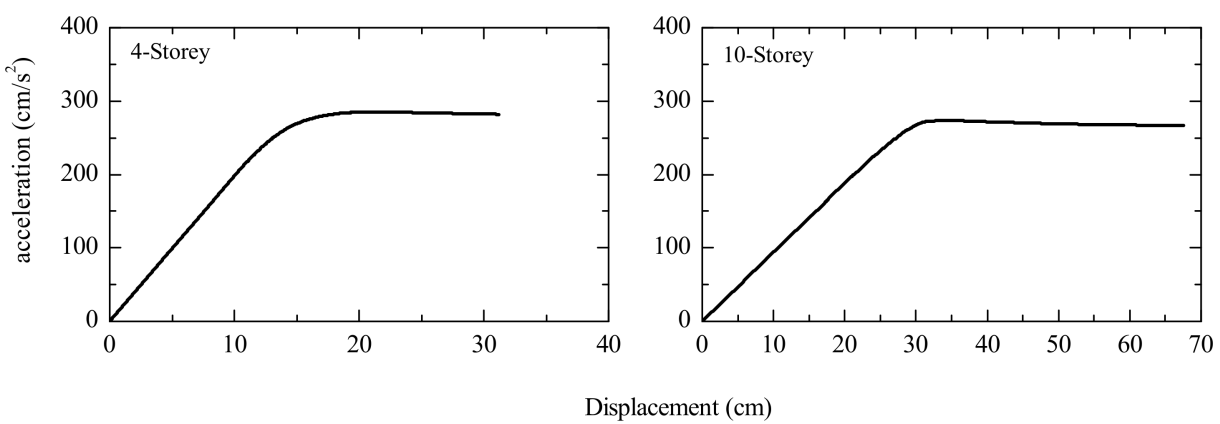

(a)

(b)

Figure 9. Capacity curve of the ESDOF of target buildings: (a) 4-story building, (b) 10-story building.

\subsection{Demand Spectrum of Earthquake Ground Motions}

The six earthquake ground motions listed in Table 8 were selected as the extreme rare earthquakes defined by the Building Standard Law of Japan [3]. The earthquakes were generated using the algorithm developed by one of the authors [32]. Three of them (No. 1,2 , and 3) were the observed earthquake records scaled to have the maximum velocity of $50 \mathrm{~cm} / \mathrm{s}$. Another three (No. 4, 5, and 6) were the artificially generated earthquake ground motions that had a response spectrum compatible with the design response spectrum of the Level-2 design earthquake and phase spectrum of the observed earthquake records. Figure 10 illustrates the acceleration response spectra, with a 5\% damping factor, of artificially generated earthquakes and the spectrum of the design code (thick solid line).

Table 8. List of selected earthquake ground motions.

\begin{tabular}{ccccc}
\hline Categories & No. & Event & Year & Station \\
\hline Scaled earthquake to be & 1 & Imperial Valley & 1940 & El Centro \\
compatible of $50 \mathrm{~cm} / \mathrm{s}$ & 2 & Kern County & 1952 & Taft \\
& 3 & Kobe & 1995 & JMA \\
\hline Artificially generated & 4 & Tohoku & 1978 & Tohoku Univ. \\
earthquake to be & 5 & Tokachi Oki & 1968 & Hachinohe \\
compatible of L2 & 6 & Kobe & 1995 & JMA \\
\hline
\end{tabular}

\subsection{Comparison Results between CSM and THA}

The maximum responses of the target buildings under the earthquake ground motions were estimated by the proposed CSM, and compared with the results of nonlinear THA. Figures 11-14 show the story drifts and story shear forces obtained by the proposed CSM and the nonlinear THA for the selected ground motions along the height of the target buildings. 


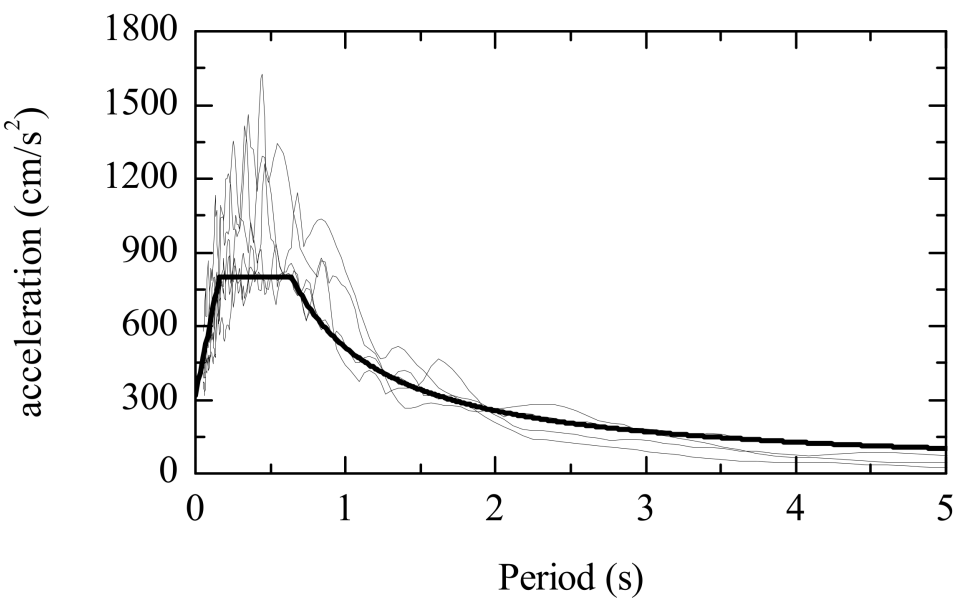

Figure 10. Response spectra of selected ground motions and design response spectrum of Level-2 earthquake with $5 \%$ damping factor.

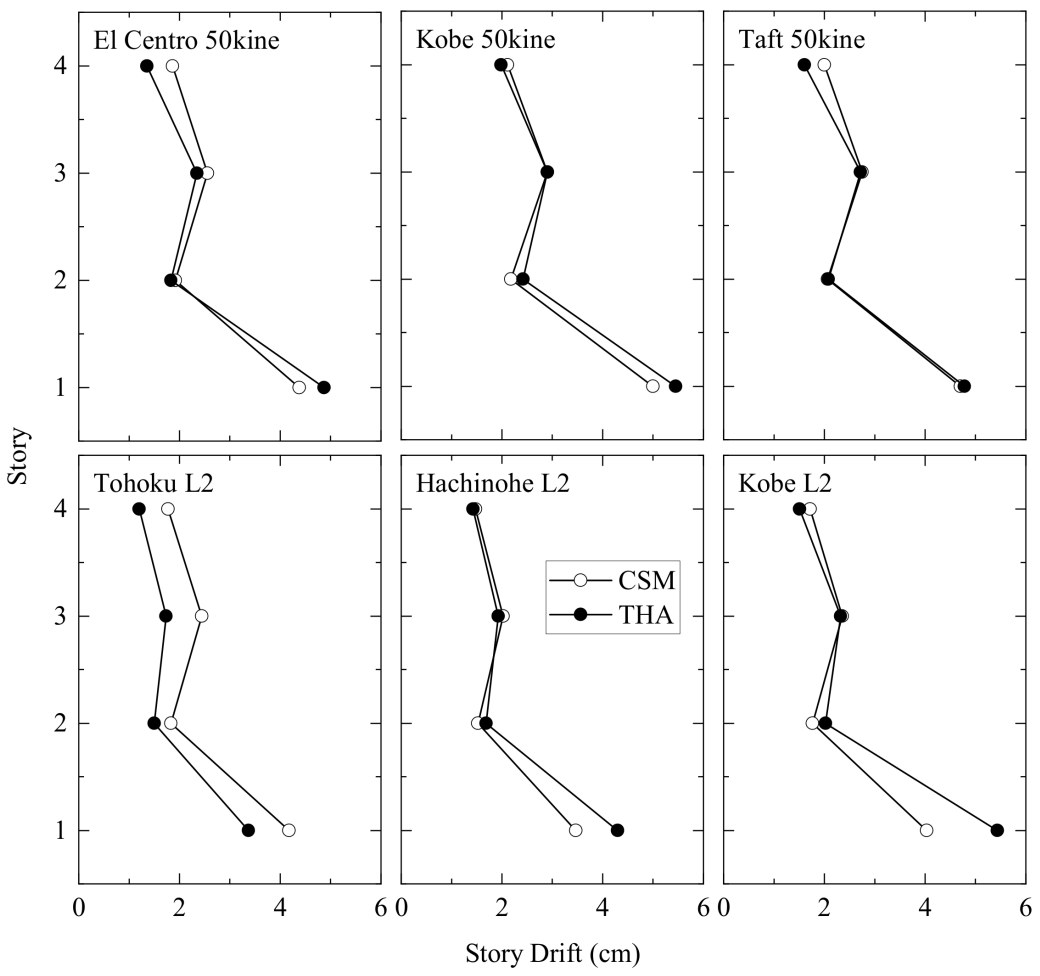

Figure 11. Comparison of story drifts between proposed CSM and time history analysis (THA) for 4-story building.

For the 4-story building, the average ratio of THA to proposed CSM (for story drift and story shear force) was 0.95 for the scaled $50 \mathrm{~cm} / \mathrm{s}$ earthquakes. The ratio for the artificially generated earthquakes compatible with Level-2 design earthquake was about 0.90 . Similarly, the ratios for the proposed CSM and the THA for story drift and story shear force, in the 10-story building, were 1.10 and 1.20 for the scaled and artificially generated ground motions, respectively. It was also noted that, for the 4-story building, the proposed CSM method overestimated the story shear force of the structure, although the story drift was underestimated for the 10-story building. Furthermore, the correlation between the performance results obtained from the proposed CSM method and THA is estimated as given in Figure 15. The estimated correlation was about 0.9 for the selected earthquakes in terms of story drift and story shear force for both of the steel buildings with oil dampers. The estimated correlation indicates that the proposed CSM can be used as a practical 
procedure to estimate the maximum responses of passively controlled buildings equipped with bilinear oil damping devices.

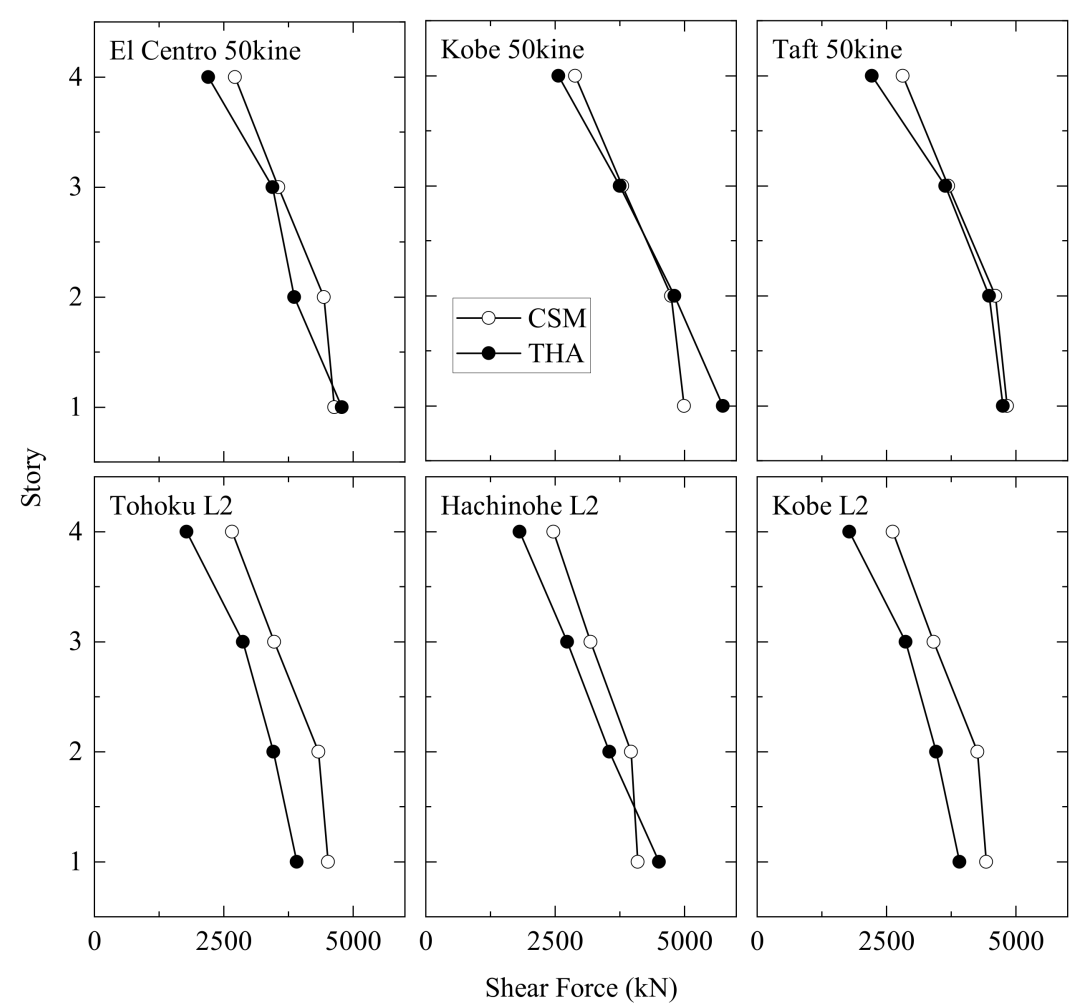

Figure 12. Comparison of story shear forces between proposed CSM and THA for 4-story building.
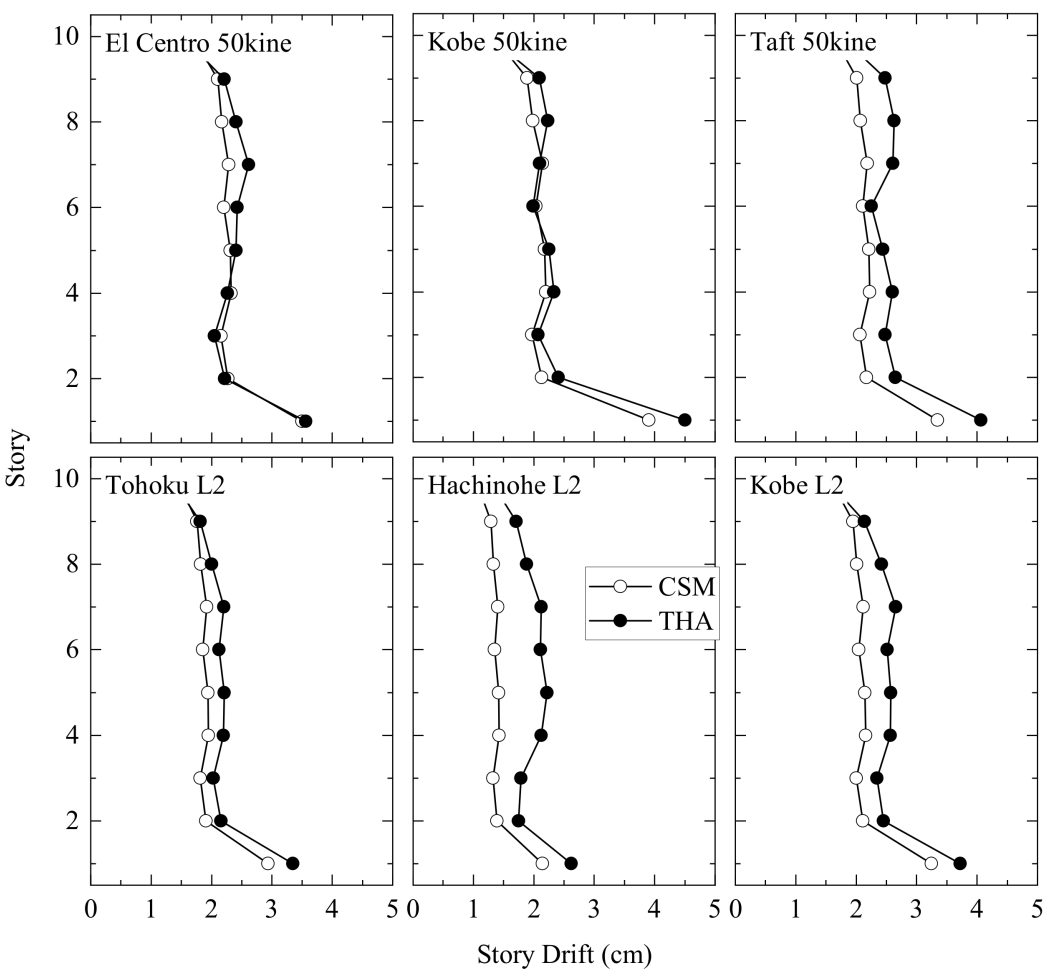

Figure 13. Comparison of story drifts between proposed CSM and THA for 10-story building. 

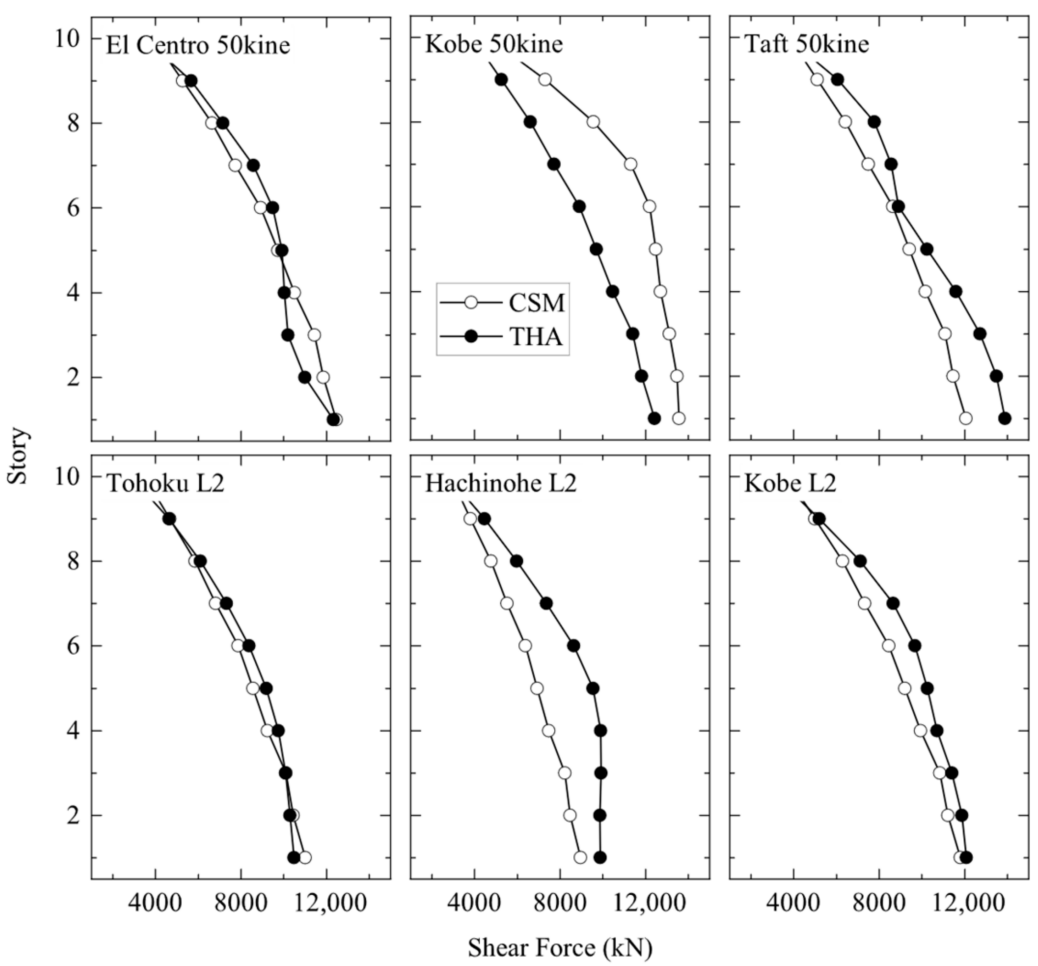

Figure 14. Comparison of story shear forces between proposed CSM and THA for 10-story building.

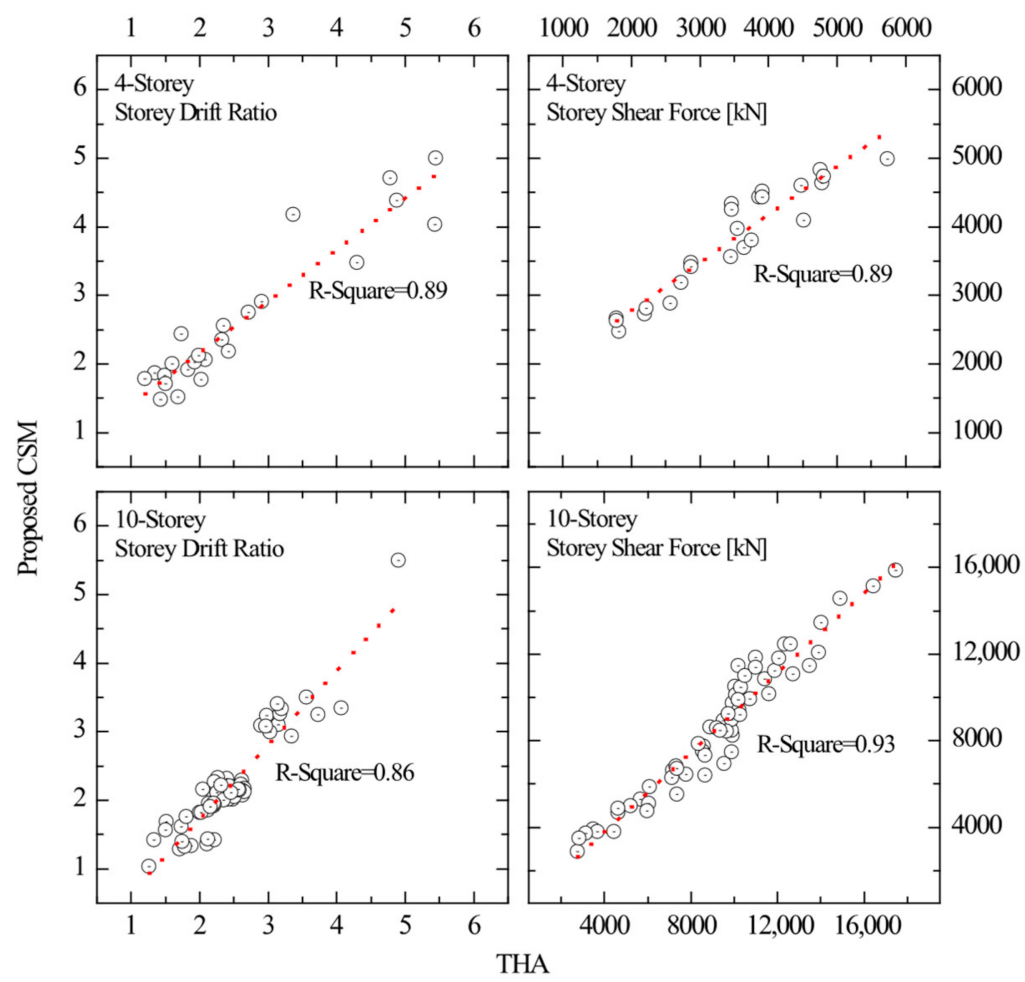

Figure 15. Story drift and shear force correlation of the proposed CSM and nonlinear THA for 4- and 10-story steel buildings.

\section{Conclusions}

A CSM-based procedure to estimate the maximum seismic response of steel buildings equipped with bilinear-type oil dampers was proposed, adopting a simple formula to calculate the effective damping ratio as the sum of the inherent damping and the SRSS 
of both supplemental viscous and hysteresis damping ratios. The required steps for the proposed CSM were given for the ESDOF system equipped with the equivalent oil dampers. Moreover, the proposed CSM was used to estimate the maximum response of two steel frame buildings of 4- and 10-stories equipped with bilinear-type oil dampers subjected to six selected Level-2 earthquake ground motions. The comparison of the maximum responses with the non-linear THA demonstrates the ability of the proposed CSM to estimate the maximum responses with an accuracy of more than $80 \%$ in all studied cases.

Author Contributions: Conceptualization, T.S. and A.N.; methodology, A.N.; software, T.S.; writingoriginal draft preparation, A.N.; writing-review and editing, T.S.; supervision, T.S. Both authors have read and agreed to the published version of the manuscript.

Funding: This research received no external funding.

Institutional Review Board Statement: Not applicable.

Informed Consent Statement: Not applicable.

Data Availability Statement: The data presented in this study are available on request from the corresponding author.

Conflicts of Interest: The authors declare no conflict of interest.

\section{References}

1. Freeman, S.A. Review of the development of the capacity spectrum method. ISET J. Earthq. Tech. 2004, 4, 1-13.

2. ATC. Seismic Evaluation and Retrofit of Concrete Buildings; Report ATC-40; ATC: Redwood City, CA, USA, 1996.

3. BSL. The Building Standard Law of Japan; The building center of Japan; BSL: Tokyo, Japan, 2004.

4. Kim, H.; Min, K.-W.; Chung, L.; Park, M.; Lee, S.-H. Evaluation of capacity spectrum method for estimating the peak inelastic responses. J. Earthq. Eng. 2005, 9, 695-718. [CrossRef]

5. Choi, H.H.; Kim, J. Evaluation of proper supplemental damping for a multi-story steel frame using capacity spectrum method. Adv. Earthq. Eng. 2001, 9, 25-34.

6. Kim, J.; Choi, H.; Min, K.-W. Performance-based design of added viscous dampers using capacity spectrum method. J. Earthq. Eng. 2003, 7, 1-24. [CrossRef]

7. Li, B.; Liang, X.-W. Design of supplemental viscous dampers in inelastic SDOF system based on improved capacity spectrum method. Struct. Eng. Mech. 2007, 27, 541-554. [CrossRef]

8. Chen, B.-J.; Chung, L.L.; Tsai, C.S.; Chiang, T.-C. Applications of capacity spectrum method for buildings with metallic yielding dampers. In Proceedings of the ASME 2005 Pressure Vessels and Piping Conference, Denver, CO, USA, 17-21 July 2005; Volume 8, pp. 299-306.

9. Han, J.; Yan, R.; Li, H. Performance-based seismic design for structures with viscoelastic dampers. J. Earthq. Eng. Eng. Vibr. 2008, 28, 175-181.

10. Benavent-Climent, A.; Escolano-Margarit, D. Shaking table tests of structures with hysteretic dampers: Experimental results versus prediction using non-linear static methods. Bull. Earthq. Eng. 2012, 10, 1857-1883. [CrossRef]

11. Kim, J.; Kim, M.; Eldin, M.N. Optimal distribution of steel plate slit dampers for seismic retrofit of structures. Steel Comp. Struct. 2017, 25, 473-484.

12. Bantilasa, K.E.; Kavvadias, I.E.; Vasiliadisb, L.K. Capacity spectrum method based on inelastic spectra for high viscous damped buildings. Earthq. Struct. 2017, 13, 337-351.

13. João, M.C. Estêvão. An Integrated Computational Approach for Seismic Risk Assessment of Individual Buildings. Appl. Sci. 2019, 9, 5088 .

14. Ferraioli, M.; Lavino, A. A displacement-based design method for seismic retrofit of RC buildings using dissipative braces. Math. Probl. Eng. 2018, 2018, 1-28. [CrossRef]

15. Naeem, A.; Kim, J. Seismic retrofit of structures using rotational friction dampers with restoring force. Adv. Struct. Eng. 2020, 23, 3525-3540. [CrossRef]

16. Ramirez, O.M.; Constantinou, M.C.; Gomez, J.D.; Whittaker, A.S.; Chrysostomou, C.Z. Evaluation of Simplified Methods of Analysis of Yielding Structures with Damping Systems. Earthq. Spectra. 2002, 18, 501-530. [CrossRef]

17. JSSI. Manual for design and construction of passively-controlled buildings. In The Japan Society of Seismic Isolation, 3rd ed.; JSSI: Tokyo, Japan, 2013. (In Japanese)

18. Kasai, K.; Kibayashi, M. JSSI manual for building passive control technology, Part-1 manual contents and design/analysis methods. In Proceedings of the 13th World Conference on Earthquake Engineering, Vancouver, BC, Canada, 1-6 August 2004; Paper No. 2989. 
19. Kibayashi, M.; Kasai, K.; Tsuji, Y.; Kikuchi, M.; Kimura, Y.; Kobayashi, T.; Nakamura, H.; Matsuba, Y. JSSI manual for building passive control technology, Part-2 criteria for implementation of energy dissipation devices. In Proceedings of the 13th World Conference on Earthquake Engineering, Vancouver, BC, Canada, 1-6 August 2004; Paper No. 2990.

20. Tsuyuki, Y.; Gofuku, Y.; Liyama, F.; Kotake, Y. JSSI manual for building passive control technology, Part-3 performance and quality control of oil damper. In Proceedings of the 13th World Conference on Earthquake Engineering, Vancouver, BC, Canada, 1-6 August 2004; Paper No. 2468.

21. Adachi, F.; Yoshitomi, S.; Tsuji, M.; Takewaki, I. Nonlinear optimal oil damper design in seismically controlled multi-story building frame. Soil Dyn. Earthq. Eng. 2013, 4, 1-13. [CrossRef]

22. Adachi, F.; Fujita, K.; Tsuji, M.; Takewaki, I. Importance of interstory velocity on optimal along-height allocation of viscous oil dampers in super high-rise buildings. Eng. Struc. 2013, 56, 489-500. [CrossRef]

23. Ji, X.; Hikino, T.; Kasai, K.; Nakashima, M. Damping identification of a full-scale passively controlled five-story steel building structure. Earthq. Eng. Struct. Dyn. 2013, 42, 277-295. [CrossRef]

24. Xie, L.; Cao, M.; Funaki, N.; Tang, H.; Xue, S. Performance study of an eight-story steel building equipped with oil dampers damaged during the 2011 great east japan earthquake part 1: Structural identification and damage reasoning. J. Asian Arch. Build. Eng. 2015, 14, 181-188. [CrossRef]

25. Takabatake, H.; Kitada, Y. Approximate method of estimating seismic performance of high-rise buildings with oil-dampers. Struct. Desig. Tall. Spec. Build. 2018, 27, 1-28. [CrossRef]

26. Chopra, A.K. Dynamics of Structures: Theory and Applications to Earthquake Engineering; Prentice Hall: Englewood Cliffs, NJ, USA, 2017.

27. Kasai, K.; Fu, Y.; Watanabe, A. Passive control systems for seismic damage mitigation. J. Struct. Eng. 1998, 124, 501-512. [CrossRef]

28. Kasai, K.; Kawanabi, Y. Equivalent linearization to predict dynamic properties and seismic peak responses of a structural system with high viscous damping and hysteretic damping. J. Struc. Cons. Eng. 2005, 591, 43-51. (In Japanese) [CrossRef]

29. Kuramoto, H.; Teshigawara, M.; Lkuzono, T.; Koshika, N.; Takayama, M.; Hori, T. Predicting the earthquake response of buildings using equivalent single degree of freedom system. In Proceedings of the 12th World Conference on Earthquake Engineering, Auckland, New Zealand, 30 January-4 February 2000; Paper No.1039.

30. Fu, Y.; Kasai, K. Comparative study on frames using viscoelastic and viscous dampers. J. Struc. Eng. 1988, 124, 513-522. [CrossRef]

31. Sekiya, E.; Mori, H.; Ohbuchi, T.; Yoshie, K.; Hara, H.; Arima, F.; Takeuchi, Y.; Saito, Y.; Ishii, M.; Kasai, K. Details of 4-, 10-, and 20-story theme structure used for passive control design examples. In The JSSI Response Control Committee Symposium on Passive Vibration Control; JSSI: Tokyo, Japan, 2004. (In Japanese)

32. Saito, T. Structural Earthquake Response Analysis, STERA_3D Version 10.8. and STERA_WAVE Version 1.0. Available online: http:/ / www.rc.ace.tut.ac.jp/saito/software-e.html (accessed on 24 December 2020). 